\title{
ОБЪЕКТИВНЫЙ ИНДИКАТОР КАЧЕСТВА ЖИЗНИ НАСЕЛЕНИЯ МОНОГОРОДОВ РОССИИ
}

\begin{abstract}
Аннотация: Одной из актуальных задач современной науке является оченка качества жизни населения. Под категорией качества жизни в соччиологии принято понимать совокупность факторов, отвечающих за субъективное и объективное восприятие бытия, удовлетворенность жизненными благами и наличие достатка. Поскольку данное понятие является чрезвычайно широким и многогранным, его относят к соччиологическим категориям, охватываюшим все сферы общества.
\end{abstract}

Ключевые слова: Сочиология, качество, жизнь, население, моногород, Россия, индикатор, факторы, блага, удовлетворенность

$\mathrm{O}$ дной из актуальных задач современной науке является оценка качества жизни населения. Под категорией качества жизни в социологии принято понимать совокупность факторов, отвечающих за субъективное и объективное восприятие бытия, удовлетворенность жизненными благами и наличие достатка. Поскольку данное понятие является чрезвычайно широким и многогранным, его относят к социологическим категориям, охватывающим все сферы общества.

Существует большое количество различных индикаторов в той или иной мере отражающих качество жизни. Среди них выделяют субъективные и объективные индикаторы, в зависимости от методов его оценки.

Объективные индикаторы качества жизни наиболее распространённые. При таком подходе качество жизни определяют через параметры объективных условий и процессов жизнедеятельности. Одним из наиболее распространённых является вариант оценки индекса развития человеческого потенциала (ИРЧП), разработанный сотрудниками Программы развития Организации Объединённых наций (ПРООН). Благодаря своей простоте и одновременно универсальности, индекс развития человеческого потенциала приобрёл широкую популярность, и сегодня многие отечественные специалисты используют его при оценке качества жизни населения. В основе отбора показателей, составляющих ИРЧП, находится идентификация базовых возможностей, которыми люди должны располагать для участия в жизни общества: возможность продолжительной и здоровой жизни, возможность и способность иметь знание и доступ к ресур- сам, необходимым для достойного уровня и качества жизни, возможность реализовать совой потенциал.

Субъективные индикаторы качества жизни строятся на субъективных оценках. Такой подход подразумевает определение качества жизни на основе социологических опросов.

Интегральные индикаторы качества жизни агрегируют в себе оба подхода - объективный и субъективный. Целью данных показателей является взвешенная оценка всех аспектов изучаемой категории без смещения на конкретный методологический подход ${ }^{1}$.

Сложность изучения качества жизни на городском уровне в России обусловлена законодательной ограниченностью данных. Без наличия релевантных и объективных данных для городов России невозможно построить объективный и, следовательно, интегральный индикатор качества жизни. Так, например, индикатор ИРЧП для Российских субъектов публикуется Министерством Регионального развития с 2003 года только на уровне областей и регионов.

Органами государственной статистики статистическая информация по основным экономическим показателям в разрезе городов формируется на основании форм федерального статистического наблюдения только по кругу крупных и средних организаций. Ограничение обусловлено действующими нормативными актами в отношении получения информации по субъектам малого предпринимательства:

\footnotetext{
${ }^{1}$ Айвазян С.А. Интегральные индикаторы качества жизни населения: их построение и использование в социально-экономическом управлении и межрегиональных сопоставлениях // С.А. Айвазян. - М. : ЦЭМИ РАН, 2000.
} 


\section{Политика и общество 5 (101) • 2013}

1) Федеральный закон от 24.07.2007 № 209-Ф3 «О развитии малого и среднего предпринимательства в Российской Федерации»;

2) Постановление Правительства Российской Федерации от 16.02.2008 № 79 «О порядке проведения выборочных статистических наблюдений за деятельностью субъектов малого и среднего предпринимательства»;

3) Федеральный план статистических работ, распоряжение Правительства Российской Федерации от 6 мая 2008 г. № 671-р в редакции от 14.02.2009 № 203-р, согласно которым текущее наблюдение осуществляется на основе выборочного метода, не позволяющего сформировать данные на муниципальном уровне.

Отдельное место среди всех городов России занимает класс моногородов. В Постановлении Правительства Российской Федерации от 14 февраля 2000 г. № 121 «О Федеральной программе государственной поддержки малого предпринимательства в Российской Федерации на 2000-2001 годы» моногорода определяются как города, образованные градообразующими предприятиями. На сегодняшний день Минрегионом России определены следующие критерии моногорода²:

- доля крупнейшего или нескольких предприятий одной и той же отрасли либо группы взаимосвязанных (или работающих на один и тот же рынок) превышает $25 \%$ численности занятых в данном населенном пункте;

- д доля одной отрасли составляет более $50 \%$ общего производства в населенном пункте;

- $\quad$ наличие в поселке городского типа предприятий определенного отраслевого профиля, как правило, создающих ситуацию экономической монопрофильности (сахарные или молочные заводы, леспромхозы и т.д.).

Моногорода в России разделяются на две группы: критические и некритические, с соответствие с социальной и экономической ситуацией в городе. В зависимости от того, к какой группе относится моногород, ему выделяется или не выделяется федеральная поддержка ${ }^{3}$. В связи с этим, изучение качества жизни населения моногородов является приоритетной задачей для муниципальных властей.

\footnotetext{
${ }^{2}$ Министерство регионального развития Российской Федерации, «Об итогах государственной поддержки моногородов» // Электронный отчет, 2010, http://www.minregion.ru/ press_office/terms/945.html.

${ }^{3}$ Там же
}

Наряду с полигородами ${ }^{4}$ России, научный анализ категории качества жизни для моногородов осложняется ограниченностью данных. Представление информации по «моногородам» пользователям может осуществляться только с соблюдением норм Федерального закона от 29 ноября 2007 г. № 282-ФЗ «Об официальном статистическом учете и системе государственной статистики в Российской Федерации» по обеспечению конфиденциальности первичных данных, представленных респондентами. Данные являются информацией ограниченного доступа, не подлежат разглашению или распространению и используются только в целях формирования официальной статистической информации.

Предоставление пользователям информации по «моногородам» ограничено обязанностью соблюдения органами государственной статистики конфиденциальности сведений, полученных от респондентов в ходе статистического наблюдения.

При этом следует отметить, что альтернативными источниками информации о социальной и экономической ситуации в моногородах являются комплексно инвестиционные планы (КИП), предоставляемые моногородами в Правительство Российской Федерации. В настоящее время поддержка моногородов осуществляется в рамках антикризисной программы Правительства Российской федерации путем разработки и последующего утверждения комплексных планов модернизации городов. Таким образом, КИП представляет собой формализованный инструмент управления рисками и мониторинга ситуации в монопрофильных муниципальных образованиях и, по существу, является ресурсообеспеченным инвестиционным пакетом проектов по уменьшению наиболее критических рисков, выявленных в ходе диагностики моногорода.

В комплексном инвестиционном плане обычно содержатся технико-экономическое обоснование и предложения относительно государственных и частных инвестиций. План может служить инструментом управления при выделении федеральных средств конкретному муниципальному образованию.

Рекомендации по структуре КИП были разработаны Министерством Регионального развития в 2007 году. В соответствие с данными рекомендациями, анализ социально экономического положения моногорода должен включать в себя следующие пункты:

\footnotetext{
${ }^{4}$ Города, отличные от моногородов.
} 
1. Анализ демографической ситуации, трудовых ресурсов, ситуации на рынке труда и в сфере занятости населения моногорода;

2. Анализ финансово-экономического положения и технологических связей градообразующего предприятия. Выявление критических рисков;

3. Местная промышленность и малый бизнес. Характеристика экономического состояния и диагностика платежеспособного спроса на работы и услуги этого сектора;

4 Социальная и техническая инфраструктура. Анализ кадровой и материально-технической и финансовой обеспеченности в сфере здравоохранения, образования, ЖКХ, транспорта и других системообразующих отраслях социальной сферы;

5. Анализ состояния бюджетной системы моногорода, в том числе доходной базы, выявление критических рисков для исполнения бюджетных обязательств.

6. Выводы, описывающие причины существующего и/или возможного (в случае не реализации мероприятий КИП) падения финансового благополучия моногорода. Экономическое обоснование и финансовые расчеты, доказывающие необходимость участия федеральных органов исполнительной власти в реализации мероприятий КИП.

На сегодняшний день КИПы представлены для большинства моногородов России и находятся в свободном доступе на официальных сайтах региональных администраций.

Оказывается, что информацию, содержащуюся в КИПе, можно использовать для довольно точной оценки индекса качества жизни ИРЧП для моногородов. Предоставляемые моногородами данные позволяют спроецировать общественно доступные региональные значения ИРЧП на городской уровень. Методология данной оценки определяется в следующих двух разделах.

\section{Индекс развития человеческого потенциала}

В основе ИРЧП лежит концепция о том, что человеку не нужен бесконечно высокий доход для обеспечения удовлетворяющей его достойной жизни. В то же время, ИРЧП придает огромное значение и самому экономическому росту, подчёркивая при этом необходимость тесной связи этого роста с развитием человека.

Специалисты ПРООН, разработавшие концепцию и методику расчёта ИРЧП, прямо утверждают, что этот индекс является показателем качества жизни населения. Эта позиция, в целом, разделяется практически всеми отечественными исследователями ${ }^{5}$, специализирующимися на проблематике качества жизни.

В соответствие с представленной методикой, данный индекс состоит из трёх компонентов: ожидаемой продолжительности жизни при рождении, уровня образования и уровня дохода, измеряемого по величине валового продукта на душу населения.

Каждый из этих трёх компонентов представляет собой результат множества взаимодействующих показателей социально-экономического развития и обладает собственной качественной характеристикой. Индекс валового продукта показывает экономическую результативность деятельности людей, индекс продолжительности жизни - состояние физического, социального и психического здоровья населения, индекс образования - социокультурный и профессиональный потенциал населения.

Общий ИРЧП рассчитывается как среднеарифметическая величина всех этих трёх индексов.

Методика расчёта ИРЧП вполне репрезентативна для оценки качества жизни населения, проведения межгородских и международных сопоставлений.

Показатель ожидаемой продолжительности жизни при рождении представляет собой число лет, которые в среднем предстояло бы прожить одному человеку из поколения родившихся при условии, что на протяжении всей жизни этого поколения уровень смертности в каждом возрасте останется таким, как в годы, для которых вычислен показатель. Для расчёта индекса ожидаемой продолжительности жизни (Ипж) условная наименьшая величина продолжительности жизни принята в 25 лет, а наибольшая - в 85 лет.

Величина Ипж региона определяется как отношение разности между продолжительностью жизни (ПЖ) в конкретном регионе за вычетом 25 лет к разнице между максимальным и минимальным возрастом и представлена в формуле ${ }^{6}$ :

$$
И_{\Pi ж}=\frac{\Pi Ж-25}{85-25}
$$

\footnotetext{
${ }^{5}$ Назарова. М.Г. Курс социально-экономической статистики: учебник для вузов // - М. : Финстатинформ, ЮНИТИДАНА, 2000.

${ }^{6}$ Баженов С.А., Маликов Н.С. Качество жизни населения: теория и практика (по результатам исследования качества жизни населения г. Белгоро-да) // Уровень жизни населения регионов России. - 2002. - № 10. - С. 1 -46.
} 


\section{Политика и общество $5(101) \cdot 2013$}

Валовый внутренний продукт (ВВП) - результирующий показатель системы национальных счетов, характеризующий стоимость товаров и услуг, произведённых в стране во всех отраслях экономики для конечного потребления, накопления и экспорта. В рамках системы национальных счетов ВВП оценивается более чем в 150 странах мира. Для учета данного показателя в ИРЧП используется нормированный ВВП на душу населения. Методика расчёта индекса ВВП (Иввп) довольно сложна в силу чрезвычайно большой дифференциации государств по этому показателю.

Минимальная и максимальная границы ВВП на душу населения для расчёта этого индекса приняты в 100 и 40000 долларов США.

Наиболее важный момент при расчёте ИРЧП заключается в учете не номинального ВВП на душу населения, а именно ВВП, рассчитанный по паритету покупательной способности (ППС). Статистический отдел ООН, в сотрудничестве с другими международными организациями, разработал еще в конце 60-х гг. методику международных сопоставлений, основанную на расчёте паритетов покупательной способности национальных валют. ППС представляет собой количество единиц валюты, необходимых для покупки некоего стандартного набора товаров и услуг, которые можно купить за одну денежную единицу базовой страны (или одну единицу общей валюты группы стран).

При расчёте Иввп используется определённый порог дохода, рассматриваемый как соответствующий разумно высокому уровню жизни. Этот порог представляет собой среднюю величину ВВП на душу населения. При расчёте ИРЧП доход до этого уровня имеет полную значимость, а доход выше этого уровня корректируется по специальной формуле.

Официальные расчёты валового регионального продукта (ВРП) начали проводиться Госкомстатом России с 1994 г. по 79 субъектам Федерации.

Образование представляет собой один из ведущих факторов формирования потребностей и интересов человека, реализация которых во многом определяет его качество жизни. В современных условиях, когда объём знаний увеличивается фактически каждые 5 - 8 лет, значимость образования растёт особенно высокими темпами. Сам экономический рост и рост потребления сегодня возможны, главным образом, за счёт развития инновационного, творческого труда ${ }^{7}$.

Уровень развития системы образования и эффективного использования образовательного потенциала населения в наиболее развитых странах мира обеспечивает до 50\% [1, с. 69] прироста валового национального продукта.

При расчёте индекса образования (И ваются две составляющие: уровень грамотности взрослого населения и совокупная доля учащихся в населении, причём первый показатель берётся с весовым коэффициентом $2 / 3$ и второй - с весовым коэффициентом $1 / 3$.

Уровень грамотности (И, определяется как процент грамотных среди взрослых жителей, т.е. среди жителей старше 15 лет. Под грамотным понимается человек, способный прочитать и написать простой текст, касающийся его повседневной жизни. Точно определить уровень грамотности населения можно только при переписях населения, но они обычно проводятся примерно достаточно редко, раз в 10 лет. Для ежегодного определения актуального уровня грамотности приходится использовать различные косвенные методы, как, например, обследование призывников или лиц, вступающих в брак. Однако вполне очевидно, что такие обследования носят выборочный характер и не дают полной и точной картины грамотности всех слоёв населения.

Совокупная доля учащчихся в населении $\left(\mathrm{И}_{\mathrm{y}}\right)$ определяется как отношение числа учащихся на всех ступенях образования, от начальной школы до аспирантуры, к числу жителей страны в возрасте от 6 до 24 лет. Важно, что в знаменателе стоит число жителей страны в определённом, юном возрасте, а в числителе число учащихся всех возрастов, вплоть до пенсионного.

Индекс образования рассчитывается по следующей формуле ${ }^{8}$ :

$$
\mathrm{U}_{\mathrm{OEP}}=\frac{2}{3} \cdot \mathrm{h}_{\mathrm{\Gamma}}+\frac{1}{3} \cdot \mathrm{U}_{\mathrm{y}}
$$

Таким образом, искомый индекс развития человеческого потенциала определяется по формуле:

\footnotetext{
${ }^{7}$ Баженов С.А., Маликов Н.С. Качество жизни населения: теория и практика (по результатам исследования качества жизни населения г. Белгоро-да) // Уровень жизни населения регионов России. - 2002. - № 10. - С. 1 - 46.

${ }^{8}$ Баженов С.А., Маликов Н.С. Качество жизни населения: теория и практика (по результатам исследования качества жизни населения г. Белгоро-да) // Уровень жизни населения регионов России. - 2002. - № 10. - С. 1 -46.
} 


$$
\text { ИРЧП }=\frac{1}{3} \cdot\left(И_{\Pi Ж}+И_{\mathrm{BB \Pi}}+\mathrm{U}_{0 \mathrm{BP}}\right)
$$

\section{Спроецированный ИРЧП для моногородов}

Анализ социально-экономического положения моногородов целесообразно рассматривать на фоне ситуации в регионе и стране в целом. Таким образом, ИРЧП для моногорода должен быть сопоставим с тем же индексом, рассчитанным для региона, к которому относится моногород. Следовательно, оценка качества жизни для моногородов строится условно на показателе регионального ИРЧП, что называется проецированием индекса на более детальный уровень.

Классический ИРЧП строится на основе трех ключевых показателей: индекса ВВП, индекса долголетия и индекса образования. Для построения спроецированного ИРЧП, необходимо построить каждый из этих индикаторов отдельно. В виду того что многие показатели, такие как ВВП, не рассчитываются на городском уровне в силу тесных взаимосвязей между городами региона, нам придется прибегнуть к оцениванию некоторых ключевых индикаторов для построения оценок ИРЧП для моногородов. Ключевыми компонентами для построения оценок должны быть региональные переменные, составляющие региональный ИРЧП, а так же индивидуальные показатели моногородов, позволяющие спроецировать региональные составляющие на городской уровень.

Индекс ВВП рассчитывается как взвешенный средний показатель ВВП на душу населения субъекта Российской Федерации во всей выборке объектов. Причем взвешенное средние рассчитывается в логарифмах по паритету покупательной способности. В силу того что ВВП есть стоимость всех товаров и услуг, произведенных за год во всех отраслях экономики на территории субъекта, он напрямую связан с доходами бюджета данного субъекта Российской федерации. Другими словами, имея данные о населении и доходах бюджета моногорода, можно с легкостью оценить значение ВВП данного моногорода. Как уже было отмечено ранее, комплексно инвестиционные планы, утвержденные для моногородов России в 2007 году, содержат информацию о состояния бюджетной системы моногорода, в том числе и доходной базы. Проводя сравнительный анализ моногородов на фоне регионов, для расчета ВВП моногорода мы используем данные о населении и доходах бюджета моногорода и его региона:

ВВП моногорода на душу $=\lambda \cdot$ ВВП региона на душу,

где коэффициент перед ВВП рассчитывается как

$\lambda=\frac{\text { Население региона }}{\text { Население моногорода }} \cdot \frac{\text { Доходы бюджета моногорода }}{\text { Доходы бюджета региона }}$

Таким образом, индекс ВВП для моногородов рассчитывается как

$И_{\mathrm{BB \Pi}}=\frac{\text { ВВП моногорода на дущу - минимальный ВВП на дущу }}{\text { максисальный ВВП на душу - минимальный ВВП на душу' }}$

Анализируя результаты расчета Иввп для основных моногородов России на фоне региональных индикаторов, мы обнаружили, что почти все моногорода отстают по данному показателю от средних региональных значений на 25\%. Объясняется это неспособностью моногородов сводить свой бюджет в профицит и постоянной дотацией моногородов из регионального бюджета. Данный факт говорит о том, что в среднем экономическая ситуация моногородов остается плачевной, не смотря на национальные проекты субсидирования и поддержки моногородов.

Индекс долголетия, рассчитывается как отношение разности между продолжительностью жизни в конкретном регионе за вычетом 25 лет к разнице между максимальным и минимальным возрастом.

Ожидаемая продолжительность жизни в городе может быть оценена по распределению возраста ухода из жизни. Однако, такая статистика для городов России в открытой печати и интернете не приводится. В связи с этим, в данной работе ожидаемая продолжительность жизни моногородов восстанавливается через возрастной состав населения моногорода, приводимый в соответствующих комплексно инвестиционных планах в анализе демографической ситуации.

Возрастной состав населения позволяет определить численность населения в различных возрастных группах и средний возраст населения в моногороде по формуле:

$$
\bar{t}=\frac{\sum_{t=1}^{100} N_{t} \cdot t}{\sum_{t=1}^{100} N_{t}}
$$

где $\mathrm{t}$ - возраст, а $N_{t}$ - число жителей данного возраста.

Число убывших в возрасте t в год $\tau$ определяется из возрастного состава по формуле: 


\section{Политика и общество $5(101) \cdot 2013$}

$N_{d}(t)=N_{t}^{\tau}-N_{t-1}^{\tau-1}$,

где $N_{t}^{\tau}$ — число жителей по возрастному составу в год $\tau$ в возрасте t, $a \boldsymbol{N}_{\boldsymbol{t}-\mathbf{t}}^{\boldsymbol{\tau}-1}-$ число жителей по возрастному составу в год $\tau-1$ в возрасте $\mathrm{t}-1$. Данная характеристика позволяет вычислить средний возраст убытия как:

$$
\overline{N_{d}(t)}=\frac{\sum_{1}^{100} N_{d}(t)}{100} .
$$

Стоит отметить, что данная величина не является в точности средней продолжительностью жизни, поскольку зависит от распределения жителей по возрасту. Она также не учитывает численность живых долгожителей, которая также влияет на величину средней продолжительности жизни.

Если отнести число убывших людей к общей численности соответствующей возрастной группы, получим распределение доли убытия в соответствующей возрастной группе.

Это доля является ни чем иным как условной вероятностью убытия в возрасте $\mathrm{t}$ при условии дожития до него - $P(t \mid t-1)$, т. е. неухода в предыдущие возрастные группы $1,2 \ldots t-1$. Условная вероятность убытия для России представлена на Графике 1.

График 1: Зависимость вероятности ухода от возраста в России

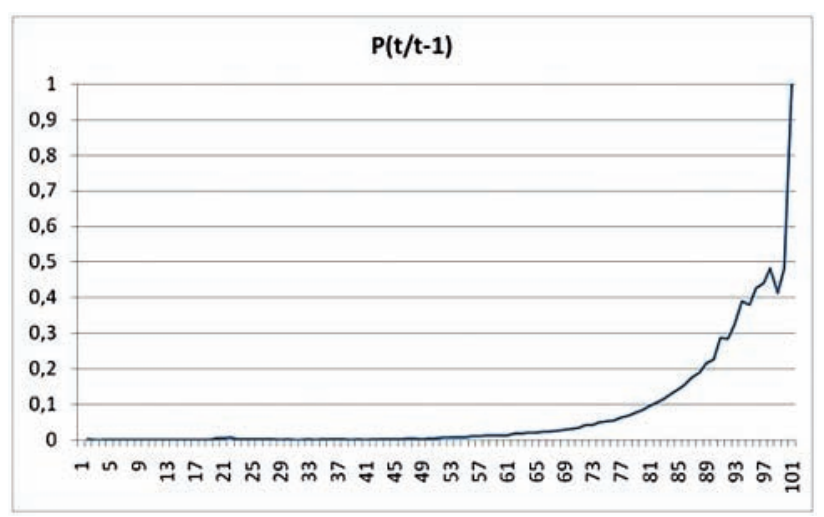

Как видно из графика, с увеличением возраста, начиная с 50 лет, вероятность убытия монотонно возрастает, что вполне объяснимо и логично. Колебания распределения в области старших возрастов обусловлены низкой статистикой долгожителей.
Для получения ожидаемой продолжительности жизни необходимо вычислить вероятность ухода в данном возрасте, которая будет равна произведению вероятности дожития до данной возрастной группы $P_{l}(t-1)$, т.е. вероятность неухода в предыдущие возрастные группы $1,2 \ldots t-1$ на условную вероятность ухода в текущей возрастной группе $\mathrm{t} P(t \mid t-1)$ :

$$
P(t)=P_{l}(t-1) \cdot P(t \mid t-1)
$$

Поскольку данный метод не учитывает смертность в возрасте до одного года, вероятность ухода в 1-й год $(\mathrm{t}=1)$ определяется как:

$P(1)=P(1 \mid 0)$

Вероятность дожития до возрастной группы t, то есть неухода в предыдущие возрастные группы $1,2 \ldots t-1$, равна произведению вероятностей неухода в каждой из предыдущих возрастных групп:

$$
\begin{aligned}
& P_{l}(t-1)=\prod_{i=1}^{t-1}(1-P(i \mid i-1)) . \\
& P(t)=\left[\prod_{i=1}^{t-1}(1-P(i \mid i-1))\right] P(t \mid t-1) .
\end{aligned}
$$

Не трудно проверить, что сумма всех вероятностей на всем интервале возрастов равна единице:

$$
\sum_{i=1}^{100} P(i)=P(1 \mid 0)+\sum_{i=2}^{100}\left[\prod_{j=1}^{i-1}(1-P(j \mid j-1))\right] P(i \mid i-1)=1 .
$$

Тогда средняя продолжительность жизни определяется как:

$$
\bar{T}=\sum_{t=1}^{100} t P(t)
$$

Анализируя результаты вычислений средней продолжительности жизни и индекса долголетия для моногородов России, мы обнаружили, что в большинстве регионов продолжительность жизни в среднем не сильно отклоняется от регионального значения. Продолжительность жизни в моногородах Уральского, Сибирского и Дальневосточного федеральных округов в среднем слегка меньше своих региональных значений на 5\%. Продолжительность жизни в моногородах Центрального, Северо-Западного и Приволжского федеральных округов в среднем равны своим региональным значениям. 
При расчёте индекса образования $\left(И_{\text {ОБр }}\right)$ учитываются две составляющие: уровень грамотности взрослого населения и совокупная доля учащихся в населении, причём первый показатель берётся с весовым коэффициентом $2 / 3$ и второй - с весовым коэффициентом $1 / 3$.

Уровень грамотности (ИГ ) определяется как процент грамотных среди взрослых жителей, т.е. среди жителей старше 15 лет. Точно определить уровень грамотности населения можно только при переписях населения. Так как данные переписи на городских уровнях не публикуются, а аккуратно оценить уровень грамотности с помощью сопутствующих показателей почти не возможно, исследование в данной работе полагает уровень грамотности в городах равным уровню грамотности в регионе в целом.

Совокупная доля учащихся в населении $\left(\mathrm{И}_{\mathrm{y}}\right)$ определяется как отношение числа учащихся на всех ступенях образования, от начальной школы до аспирантуры, к числу жителей субъекта Российской федерации в возрасте от 6 до 24 лет. Данные о социальной и технической инфраструктурах в комплексно инвестиционных планах моногородов России позволяют оценить долю уча-

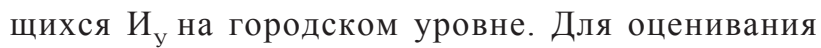
доли учащихся в моногородах мы используем данные о количестве учебных заведений и учебных мест на 1 жителя:

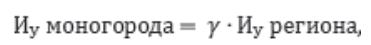

где коэффициент пропорциональности рассчитывается как:

$$
\gamma=\frac{\text { Население региона }}{\text { Население моногорода }} \cdot \frac{\sum_{\text {моногород }} \beta_{i} \cdot \text { Учебное заведение } i}{\sum_{\text {регион }} \beta_{j} \cdot \text { Учебное заведение } j},
$$

где $\beta_{\mathrm{i}}$ - весовой коэффициент в взвешенной сумме, равный количеству учебных мест в учебном заведении i.

Таким образом, индекс образования в моногороде рассчитывается по следующей формуле:

$$
\mathrm{U}_{\mathrm{OEP}}=\frac{2}{3} \cdot \mathrm{U}_{\mathrm{\Gamma}}+\frac{1}{3} \cdot \gamma \cdot \mathrm{U}_{\mathrm{y}}
$$

Анализируя результаты расчета индекса образования для моногородов России, мы обнаружили, что в большинстве регионов индекс образования моногородов незначительно ниже региональных значений, что есть результат сглаживания значений индексом грамотности $И_{\Gamma}$. Данный факт подтверждает, что финансирование образования в моногородах несколько ниже чем в среднем по региону, что является закономерным выводом из анализа бюджета моногородов. К тому же, если обратить внимание на занижен-

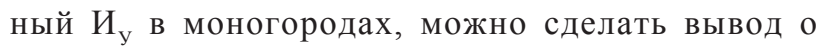
невостребованности квалифицированных специалистов на рынке труда в моногороде. Молодые специалисты в условиях отсутствия рабочих мест за пределами градообразующих предприятий зачастую стараются найти работу как можно раньше, упуская возможность получить необходимое образование.

Вычислив все три ключевых показателя качества жизни моногородов, легко оценить искомый показатель качества жизни ИРЧП как среднее арифметическое данных индексов:

$$
\text { ИРЧП }=\frac{1}{3} \cdot\left(И_{\text {ПЖ }}+U_{\text {BвП }}+U_{\text {OБР }}\right)
$$

Анализируя результаты расчета спроецированного ИРЧП для моногородов, мы обнаружили, что объективное качество жизни в моногородах значительно меньше, чем в среднем по регионам, а значит и меньше, чем в среднем в других полиструктурных городах. В большинстве моногородов качество жизни меньше на $20-25 \%$ чем в своих регионах (среднее значение $22 \%$ ). Основной причиной заниженного ИРЧП является слабая бюджетная позиция моногородов, что напрямую связано с доходами градообразующих предприятий. Составляя более $50 \%$ доходов городского бюджета, налоги от доходов градообразующих предприятия зачастую связаны с рыночной конъюнктурой. Таким образом, текущий период, демонстрирующий замедление экономического роста, значительно усугубил качество жизни моногородов России, не смотря на попытку властей оказывать помощь моногородам из федерального бюджета. Правильные действия были предприняты в составлении долгосрочных планов развития моногородов и градообразующих предприятий. Однако на сегодняшний день плоды этой политики оценивать пока еще рано. Объективное качество жизни все еще остается на низком уровне. 


\section{Политика и общество $5(101) \cdot 2013$}

График 2: ИРЧП моногородов Центрального федерального округа

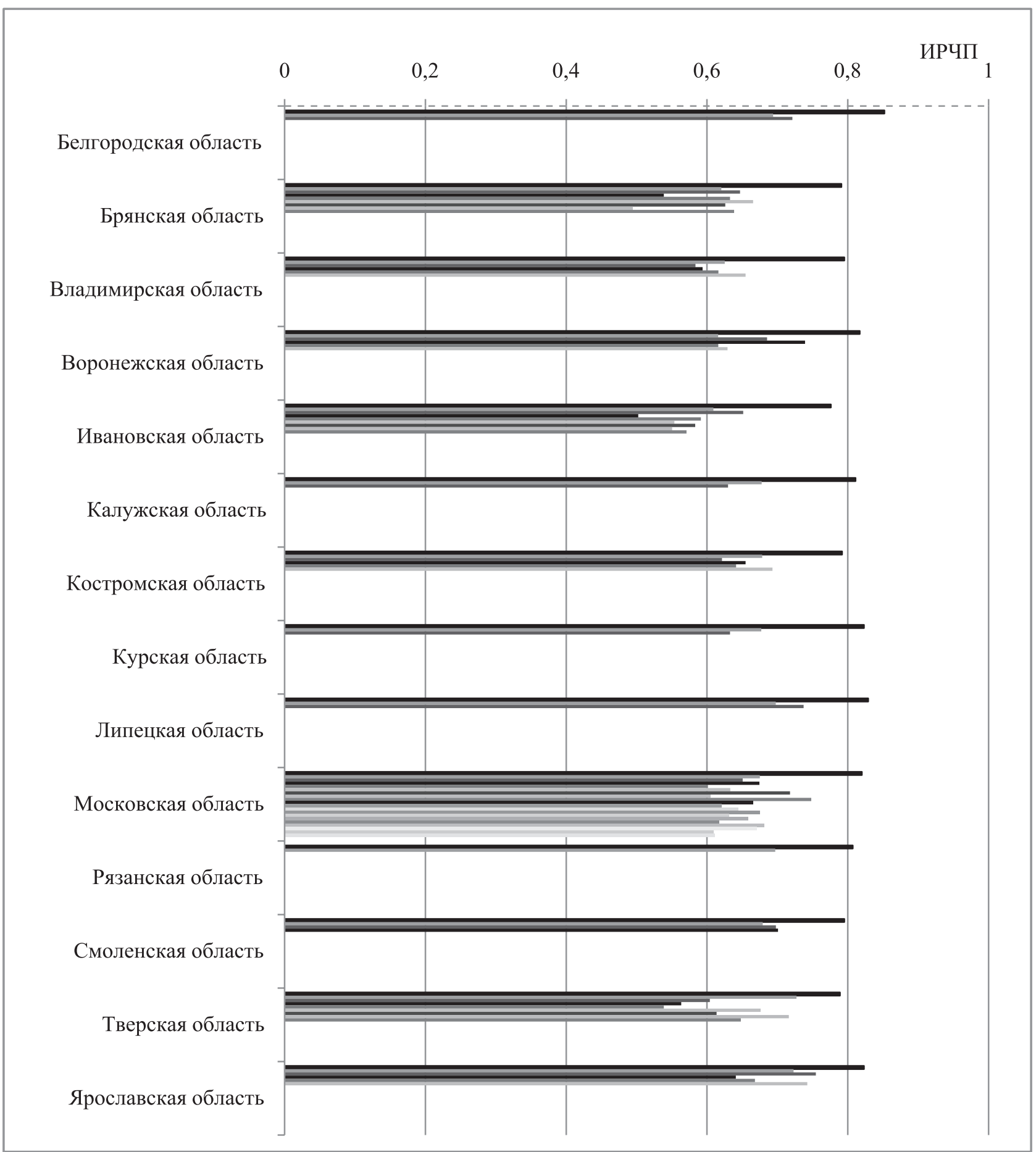

Примечание: Первая (черная) колонка в каждой области обозначает уровень ИРЧП области. Серые колонки под ней обозначают уровень ИРЧП моногородов в этой области. 
На Графике 2 наглядно продемонстрировано отставание уровня спроецированного ИРЧП для моногородов Центрального федерального округа от региональных значений. Черная колонка есть уровень ИРЧП области в целом, а серые колонки под ней обозначают уровень ИРЧП моногородов в каждой области. Как видно из графика, наихудшее качество жизни моногородов наблюдается в Брянской, Ивановской и Тверской областях. Качество жизни в моногородах этих регионов в среднем меньше региональных значений на $24 \%, 26 \%$ и $20 \%$ соответственно.

Аналогичный анализ также был проведен для моногородов других федеральных округов России:

- В Северо-Западном федеральном округе наихудшая ситуация в моногородах наблюдается в республике Карелия. Качество жизни в моногородах Карелии в среднем на 30\% ниже, чем во всем регионе.

- В Южном федеральном округе в негативном аспекте выделяется Краснодарский край. Качество жизни в моногородах Краснодарского края в среднем на 24\% ниже, чем во всем регионе.

- В Приволжском федеральном округе качество жизни во всех регионах выглядит примерно одинаково. Отставание от региональных значений составляет порядка 20\% во всех регионах Приволжского округа. Этот показатель является наименьшим среди всех федеральных округов.

- В Уральском федеральном округе выделяется Курская область с отставанием качества жизни моногородов на 21\%.

- В Сибирском федеральном округе выделяются Иркутская область и Забайкальский край. Качество жизни в данных регионах отстает от региональных значений на $22 \%$ и $25 \%$ соответственно.

- В Дальне-Восточном федеральном округе наихудшая ситуация в моногородах наблюдается в республике Саха (Якутия). Качество жизни в моногородах Якутии в среднем на 25\% ниже, чем в самом регионе.

\section{Библиография:}

1. Андрианов В.Д. Проблемы отраслевой, межотраслевой и региональной экономики // Вестник Моск. ун-та. Сер 6, Экономика. - 1998. - № 72. - C. 69.
2. Айвазян С.А. Анализ синтетических категорий качества жизни населения субъектов Российской Федерации: их измерение, динамика, основные тенденции // Уровень жизни населения регионов России.-2002.-№11

3. Айвазян С.А. Интегральные индикаторы качества жизни населения: их построение и использование в социально-экономическом управлении и межрегиональных сопоставлениях // С.А. Айвазян. М. : ЦЭМИ РАН, 2000.

4. Баженов С.А., Маликов Н.С. Качество жизни населения: теория и практика (по результатам исследования качества жизни населения г. Белгорода) // Уровень жизни населения регионов России. - 2002. - № 10. - С. 1 -46.

5. Егоршин А.П., Львов Д.С., Гранберг А.Г. Стратегическое управление: регион, город, предприятие // ООН РАН, НИМБ. - М. : ЗАО «Издательство Экономика», 2004. - 605 с.

6. Назарова. М.Г. Курс социально-экономической статистики : учебник для вузов // - М. : Финстатинформ, ЮНИТИ-ДАНА, 2000.

7. Министерство регионального развития Российской Федерации, «Об итогах государственной поддержки моногородов» // Электронный отчет, 2010, http://www.minregion.ru/press_office/ terms/945.html.

\section{References (transliteration):}

1. Andrianov V.D. Problemy otraslevoy, mezhotraslevoy i regional'noy ekonomiki // Vestnik Mosk. un-ta. Ser 6, Ekonomika. - 1998. - № 72. - S. 69.

2. Ayvazyan S.A. Analiz sinteticheskikh kategoriy kachestva zhizni naseleniya sub'ektov Rossiyskoy Federatsii: ikh izmerenie, dinamika, osnovnye tendentsii // Uroven' zhizni naseleniya regionov Rossii.-2002.-№11

3. Ayvazyan S.A. Integral'nye indikatory kachestva zhizni naseleniya: ikh postroenie i ispol'zovanie v sotsial'no-ekonomicheskom upravlenii i mezhregional'nykh sopostavleniyakh // S.A. Ayvazyan. - M. : TsEMI RAN, 2000.

4. Bazhenov S.A., Malikov N.S. Kachestvo zhizni naseleniya: teoriya i praktika (po rezul'tatam issledovaniya kachestva zhizni naseleniya g. Belgoro-da) // Uroven' zhizni naseleniya regionov Rossii. - 2002. № 10 . - S. $1-46$. 
DOI: $10.7256 / 1812-8696.2013 .05 .7$

\section{Политика и общество 5 (101) • 2013}

5. Egorshin A.P., L'vov D.S., Granberg A.G. Strategicheskoe upravlenie: region, gorod, predpriyatie//OONRAN, NIMB. - M. : ZAO «Izdatel'stvo Ekonomika», 2004. - 605 s.
6. Nazarova. M.G. Kurs sotsial'no-ekonomicheskoy statistiki : uchebnik dlya vuzov // - M. : Finstatinform, YuNITI-DANA, 2000. 